\title{
As metáforas em Verdade e Coração: estudo contrastivo do léxico fraseológico a partir de um corpus paralelo
}

The metaphors in Truth and Heart: a comparative study of the phraseological lexicon from a parallel corpus

\author{
Marilei Amadeu Sabino \\ Adriane Orenha-Ottaiano \\ Ariane Donizete Delgado Ribeiro Caldas
}

Instituto de Biociências, Letras e Ciências Exatas - IBILCE - UNESP - São Paulo - Brasil

\begin{abstract}
Resumo: O presente trabalho tem por objetivo analisar o léxico fraseológico formado pelas lexias verdade e coração em um corpus paralelo composto pelas legendas em inglês e português de cinco temporadas do seriado norte-americano Gossip Girl, a fim de evidenciar as metáforas conceptuais subjacentes a estas combinatórias e de contrastar as manifestações linguísticas metafóricas oriundas destas duas lexias em ambos os idiomas em tela. Para a análise, contamos com o suporte metodológico do programa Word Smith Tools, versão 6.0 (SCOTT, 2012), o qual nos possibilitou a identificação e extração do léxico fraseológico composto por metáforas conceptuais presentes no referido seriado. Dessa forma, foi possível identificarmos um total de doze metáforas conceptuais diferentes nas unidades fraseológicas constituídas pelas lexias verdade e coração e truth e heart. Espera-se, assim, ter sido possível evidenciar a presença das metáforas conceptuais em unidades fraseológicas, ressaltando a importância das metáforas para a Fraseologia.
\end{abstract}

Palavras-chave: Fraseologia. Metáfora. Metáfora conceptual. Léxico fraseológico.

\begin{abstract}
This paper aims to carry out the analysis of the phraseological lexicon formed by the words truth and heart and their translations into Portuguese taken from a parallel corpus composed by the subtitles in English and Portuguese of five seasons of the American series Gossip Girl, in order to identify the conceptual metaphors underlying these combinations and to contrast the linguistic metaphorical manifestations in both studied languages. For the analysis, we have the methodological support of Word Smith Tools, version 6.0 (SCOTT, 2012), which enabled us to identify and extract the phraseological lexicon composed of conceptual metaphors present in the series. In this way, it was possible to identify a total of twelve different conceptual metaphors in the phraseological units constituted by the lexias verdade and coração and truth and heart. It is hoped, therefore, to have been possible to evidence the presence of the conceptual metaphors in phraseological units, emphasizing the importance of the metaphors for the Phraseology.
\end{abstract}

Keywords : Phraseology. Metaphor. Conceptual Metaphor. Phraseological Lexicon. 


\section{Introdução}

O estudo publicado por Pérez (2009) sobre as metáforas conceptuais acerca da lexia coração foi o motivador para a realização da pesquisa apresentada neste artigo. Contudo, diferentemente do estudo empreendido pela autora, buscaremos contrastar as manifestações linguísticas das metáforas conceptuais de heart e truth e de seus correspondentes em português verdade e coração, a partir de um corpus de estudo composto pelas legendas do seriado norteamericano Gossip Girl.

Optamos por trabalhar com 0 corpus composto pelas legendas deste seriado, de forma a verificar como se dá a relação metafórica presente no léxico fraseológico em diálogos cotidianos. Assim, contamos com um corpus paralelo, formado pelas legendas em inglês e português do referido seriado, 0 que nos permite empreender um estudo contrastivo sobre as manifestações linguísticas das metáforas em ambos os idiomas, além de permitir verificar se as metáforas conceptuais que regem estas manifestações linguísticas são as mesmas em ambos os idiomas.

Ressalta-se que a escolha das lexias heart e coração teve como base o estudo empreendido por Pérez (2009), além de serem dois lexemas bastante frequentes no corpus Gossip Girl. Partindo do mesmo princípio de frequências, foram selecionadas as lexias truth e verdade.

A seguir, apresentamos os postulados teóricos que embasaram esta pesquisa.

\section{Pressupostos teóricos}

\subsection{Metáfora}

Embora seja comum conceber a metáfora como uma figura de linguagem amplamente usada em textos literários e poéticos, Lakoff e Johnson ([1980] 2003, p. 5) acreditam que "a essência da metáfora é entender e experienciar um tipo de coisa em termos de outra"1, ou seja, a metáfora ajuda-nos a entender conceitos que demandariam maior complexidade de expressão por serem, em alguns casos, abstratos demais. Sendo assim, acreditam e defendem que

(...) as metáforas não são apenas uma questão de linguagem, ou seja, de meras palavras. [...], ao contrário, os processos de pensamento humano são amplamente metafóricos. É isto que queremos dizer ao afirmar que o sistema conceptual humano é metaforicamente estruturado e definido. As metáforas como expressões linguísticas são possíveis precisamente porque elas são metáforas no sistema conceptual de uma pessoa. [...], devemos entender metáfora como conceito metafórico. ${ }^{2}$ (LAKOFF; JOHNSON, [1980] 2003, p. 6)

Como se pode perceber, as metáforas, segundo os autores, vão muito além das manifestações linguísticas poéticas que estudamos nas aulas de língua portuguesa até o ensino médio. Ao conceber a metáfora como um sistema conceptual que está intimamente ligado aos processos de pensamento humano, eles conseguem provar que as metáforas estão presentes em nosso cotidiano sem que consigamos nos dar conta disso.

Segundo os autores, as metáforas conceptuais perpassam os indivíduos que compartilham de uma mesma cultura. Para provar esta constatação, usam o exemplo da metáfora conceptual ARGUMENTO É GUERRA, a qual é facilmente compreendida pela cultura ocidental, habituada a diversas guerras, nas quais sempre há um vencedor, alguém que impõe sua vontade, tal como acontece em uma discussão; contudo, ela poderia não ser compreendida, ou receber outras características caso estivesse inserida em uma cultura que a visse como uma

\footnotetext{
1 "The essence of metaphor is understanding and experiencing one kind of thing in terms of another."

2 "(...) metaphor is not just a matter of language, that is, of mere words. [...], on the contrary, human thought processes are largely metaphorical. This is what we mean when we say that the human conceptual system is metaphorically structured and defined. Metaphors as linguistic expressions are possible precisely because there are metaphors in a person's conceptual system. [...], it should be understood that metaphor means metaphorical concept. (Grifos do original)."
} 
dança, por exemplo. (LAKOFF; JOHNSON, [1980]2003, p. 4-5)

Dessa forma, os autores categorizam as metáforas conceptuais em metáforas orientacionais, regidas pelas direções, como para cima, para baixo, para dentro; metáforas ontológicas, as quais compreendem as metáforas de entidade e substância e as metáforas de recipientes, entre outras.

Mena e Bertrán (2002), ao discorrerem sobre a teoria proposta por Lakoff e Johnson (1980), concordam com a definição da essência da metáfora dada por estes, e afirmam, inclusive, que "é típico dos conceitos emocionais não estarem claramente delineados e terem que ser compreendidos por meio das metáforas"3 (MENA; BERTRÁN, 2002, p. 69), fato que corrobora a necessidade que temos de fazer uso da metáfora não só em nosso falar, mas também em nosso pensar.

Dessa forma, tendo em vista as especificidades de nosso próprio corpus de estudo, daremos atenção ao uso das metáforas conceptuais defendidas por Lakoff e Johnson ([1980] 2003), mais precisamente, focaremos nas metáforas ontológicas, visto que "uma vez que podemos identificar nossas experiências como entidades ou substâncias, podemos nos referir a elas, categorizálas, agrupá-las e quantificá-las - e, por estes meios, pensar sobre elas"4 (LAKOFF; JOHNSON, [1980] 2003, p. 25).

Assim, em nossa pesquisa, nos pautamos nas explicações acerca das metáforas ontológicas, a fim de classificar nossas ocorrências sob uma mesma metáfora conceptual, visto que, "o esteio para as metáforas ontológicas está na relação das nossas experiências com objetos físicos" (BARBOSA, 2014, p. 59).

\footnotetext{
3 "Es típico de los conceptos emocionales el no estar claramente delineados y tener que ser comprendido por medio de las metáforas."

4 "Once we can identify our experiences as entities or substances, we can refer to them, categorize them, group them, and quantify them - and, by this means, reason about them."
}

\subsection{Fraseologia e Metáfora}

Ao apresentar as características das unidades fraseológicas, Zuluaga (1980) trata da idiomaticidade, a qual, segundo o autor, é "apreciada como uma anomalia ou peculiaridade, no plano da combinação das unidades léxicas" (ZULUAGA, 1980, p. 122). Para o autor, a idiomaticidade é uma das características mais importantes das unidades fraseológicas, sendo definida por ele como "o traço semântico próprio de certas construções linguísticas fixas, cujo sentido não pode ser estabelecido a partir dos significados de seus elementos componentes nem do de sua combinação"6 (idem).

Considerando-se a definição de idiomaticidade trazida por Zuluaga (1980) e tomando a afirmação de Corpas Pastor (1997) de que "as unidades fraseológicas podem apresentar dois tipos de significado denotativo: significado denotativo literal e significado denotativo figurativo"7, sendo este significado figurativo definido pela autora como produto de "processos metafóricos ou metonímicos (ou ambos conjuntamente) ") (CORPAS PASTOR, 1997, p. 27), pode-se perceber que a metáfora e a fraseologia conservam uma relação de proximidade desde o início dos estudos fraseológicos, embora Zuluaga não tenha utilizado o termo metáfora ao explicar a idiomaticidade.

No entanto, Tristá, já em 1988, ao referir-se as unidades fraseológicas, ressaltava que "a metáfora é o fator semântico por excelência que atua na formação destas unidades", uma vez que a "metaforização, ou seja, a mudança de sentido originada pela semelhança entre fenômenos e objetos, é uma das maiores forças de

\footnotetext{
5 “(...) es apreciada como una anomalia o peculiaridad, en el plano de la combinación de las unidades léxicas, (...)."

"(...) el rasgo semántico propio de ciertas construcciones lingüísticas fijas, cuyo sentido no puede establecerse a partir de los significados de sus elementos componentes ni del de su combinación, (...)."

7 "Las unidades fraseológicas pueden presentar dos tipos de significado denotativo: significado denotativo literal y significado denotativo figurativo (...)."

"(...) procesos metafóricos o metonímicos (o ambos cunjuntamente), (...)."

9 "(...) la metáfora es el factor por excelencia que actúa en la formación de estas unidades."
} 
enriquecimento da fraseologia"10 (TRISTÁ, 1988, p.

21).

Percebe-se assim, que a presença da metáfora sempre foi de suma importância para a fraseologia, havendo divergência, apenas, quanto à nomenclatura utilizada pelos autores da área.

Neste sentido, os escritos de Mena e Bertrán (2002) vêm reafirmar a relação que a Fraseologia mantém com a metáfora, uma vez que

A fraseologia está composta, sobretudo por metáforas, já que suas formas pluriverbais representam em bloco um conceito a partir de outro [...]. A projeção metafórica tem sido mencionada como uma propriedade definidora dos fraseologismos: [...]. ${ }^{11}$ (MENA; BERTRÁN, 2002, p. 87).

Conforme mencionado anteriormente, Mena

e Bertrán empreenderam um estudo sobre fraseologia e metáforas, buscando evidenciar e classificar as metáforas conceptuais, ou arquimetáforas, tal como as denominam, que perpassam o léxico fraseológico. Neste estudo, os autores afirmam ainda que a proposta experiencialista de Lakoff e Johnson de 1980 foi de grande importância para a Fraseologia, visto que

Destacam a função da metáfora nos processos cognitivos como recurso que facilita a conceptualização, estruturação do significado, mediante a projeção de um conceito sobre outro e, portanto, como fator ativo em nossa compreensão do mundo. (MENA; BERTRÁN, 2002, p. 57)

Dessa maneira, tomando por base estes pressupostos teóricos sobre metáfora e fraseologia, analisamos o léxico fraseológico obtido em nosso corpus de estudo, buscando a verificação da presença de metáforas conceptuais e, abaixo, descrevemos a metodologia empregada para tal análise.

\footnotetext{
10 "La metaforización, es decir, el cambio de sentido originado por la semejanza entre fenómenos $u$ objetos, es una de las mayores fuerzas de enriquecimiento de la fraseología."

11 "La fraseología está compuesta sobre todo por metáforas, ya que sus formas pluriverbales representan en bloque un concepto a partir de otro [...]. La proyección metafórica ha sido mencionada como una propiedad definitoria de los fraseologismos: [...]."
}

\section{Metodologia}

Para o desenvolvimento desta pesquisa, optou-se por um corpus paralelo constituído pelas legendas em inglês e português das cinco primeiras temporadas do seriado Gossip Girl, tendo em vista que este tipo de corpus permite uma "correspondência frase por frase entre os dois textos"12 (TOGNINI-BONELLI, 2002, P. 6-7). Para compilá-lo, levamos em consideração alguns aspectos importantes, tais como: representatividade da língua, propósito de pesquisa linguística, e ocorrência natural. Dessa forma, seguiu-se aqui a definição de corpus dada por Tognini-Bonelli (2002, p.2):

Um corpus pode ser definido como uma coleção de textos que assumem ser representativos de uma dada língua, reunidos de forma que possam ser usados para análise lingüística. Normalmente, pressupõe-se que a língua armazenada em um corpus é de ocorrência natural, que é compilada de acordo com os critérios do projeto, com um propósito específico em mente, e com a pretensão de representar os 'pedaços maiores do idioma' selecionado de acordo com uma tipologia específica. (TOGNINI-BONELLI, 2002, p.2). ${ }^{13}$

Consideramos nosso corpus de estudo representativo de ambos os idiomas em estudo, em razão de ser um corpus de extensão relativamente grande (7.547.494 palavras no corpus de língua inglesa e 6.621 .981 palavras no corpus de língua portuguesa), assim como pelo fato de se tratar das legendas de um seriado de TV norte-americano voltado para o público adolescente/jovem, dado este que colabora, também, no aspecto de ocorrência natural dos textos, uma vez que o seriado enfoca a maneira de falar dos jovens americanos de classe média-alta, retratando a vida de adolescentes milionários em suas respectivas escolas, havendo

\footnotetext{
12 “(...), sentence-by-sentence correspondence between the two texts."

13 " $[. .$.$] A corpus can be defined as a collection of texts$ assumed to be representative of a given language put together so that it can be used for linguistic analysis. Usually the assumption is that the language stored in a corpus is naturally-occurring, that is gathered according to explicit design criteria, with a specific purpose in mind, and with a claim to represent larger chunks of language selected according to a specific typology."
} 
também a presença de adolescentes da classe média interagindo com os demais. Dessa forma, o corpus de estudo atende a outro aspecto importante proposto por Tognini-Bonelli (2002), o propósito de pesquisa linguística, já que, por meio de amostras de uso da língua geral, extraímos as informações relacionadas ao conteúdo metafórico constituído pelas lexias verdade e coração, em ambos os idiomas, para, depois, procedermos à análise e identificação das metáforas conceptuais.

Para a análise das lexias mencionadas acima, utilizamos o programa WordSmith Tools, versão 6.0 (SCOTT, 2012). Este programa é composto por três ferramentas principais, a saber, WordList, KeyWords e Concord. Em nossa pesquisa utilizamos as ferramentas WordList, a qual gera uma lista de palavras na qual é possível verificar a frequência com que cada palavra ocorre no corpus de estudo, e que nos permitiu verificar que a lexia truth ocorre 262 vezes, enquanto heart ocorre 148 vezes no corpus de estudo em inglês; e que a lexia verdade ocorre 977 vezes, enquanto coração ocorre 89 vezes em nosso corpus de estudo em português.

Após esta etapa, passamos para a análise feita por meio da ferramenta Concord, a qual nos permitiu verificar os contextos de cada ocorrência das lexias em análise. Por meio da análise empreendida neste momento da pesquisa, foi possível chegar aos exemplos que são apresentados na sessão posterior, além de poder agrupá-los sob algumas metáforas conceptuais, as quais também são apresentadas na próxima sessão.

Convém ressaltar que não utilizamos a ferramenta KeyWords em nossa pesquisa, pois, ao começar a trabalhar com nosso corpus de estudo, já havíamos delimitado as lexias truth/heart e verdade/coração para empreender nossa pesquisa, tomando como base para tal o estudo empreendido por Pérez (2009) sobre as metáforas do coração. Além disso segundo mencionamos anteriormente, devido à alta ocorrência da lexia verdade, optamos por analisá-la também, em ambos os idiomas em foco.

A seguir, apresentamos os dados obtidos por meio da análise descrita.

\section{Análise dos dados}

Nesta seção, apresentamos a análise feita a partir dos dados advindos da observação das palavras truth/verdade e heart/coração em nosso corpus de estudo, de forma a identificar as metáforas conceptuais que regem o léxico fraseológico levantado e, consequentemente, evidenciar as manifestações linguísticas encontradas nos dois idiomas observados, inglês e português, visto que, conforme mencionamos, contamos com um corpus paralelo para 0 desenvolvimento desta pesquisa.

\subsection{Truth/Verdade}

A partir da análise em nosso corpus de estudo em inglês da lexia truth, obtivemos um total de 262 ocorrências, tendo sido possível a identificação de traços metafóricos para esta lexia em apenas 39 ocorrências. Já, em nosso corpus em português, obtivemos um total de 977 ocorrências para verdade, sua lexia correspondente, sendo que, após a análise destas, chegamos apenas a 31 ocorrências nas quais a lexia buscada (verdade) é apresentada com algum traço metafórico.

Conforme podemos perceber, a diferença quanto ao número total de ocorrências encontradas nos dois corpora de estudos é bastante considerável. Isto se deve ao fato de, em alguns casos, a lexia verdade ter sido usada para a tradução de outras lexias do inglês, como true, por exemplo, além de ter sido empregada para traduzir a lexia truth, dado este que pode ser explicado pelas diferenças de referenciais culturais e metafóricas em ambos os idiomas, as quais não serão abordados nesta pesquisa, devido ao enfoque de busca dado a ela.

Desse modo, após analisarmos as frases com conteúdo metafórico em ambos os corpora de estudos, podemos afirmar que encontramos cinco metáforas conceptuais que perpassam o léxico fraseológico estudado, sendo que, em alguns casos, a metáfora conceptual foi identificada apenas em um de nossos corpora de estudos. 
A seguir, apresentamos os quadros de identificação do conteúdo fraseológico com as metáforas conceptuais.

Começamos com os quadros que demonstra a metáfora conceptual $A$ verdade é um lugar.

\begin{tabular}{|l|l|}
\hline \multicolumn{2}{|c|}{ Metáfora Conceptual: A verdade é um lugar } \\
\hline Corpus Inglês & Corpus Português \\
\hline $\begin{array}{l}\text { But that couldn't be } \\
\text { further from the truth. }\end{array}$ & - \\
\hline $\begin{array}{l}\text { It isn't speaking to some } \\
\text { deeper truth. }\end{array}$ & - \\
\hline
\end{tabular}

Quadro 1: Metáfora conceptual a verdade é um lugar

Percebe-se, a partir do quadro apresentado, que foram encontradas apenas duas ocorrências desta metáfora conceptual em nosso corpus de estudo em inglês, e nenhuma ocorrência correspondente em nosso corpus de língua portuguesa, fato que pode ser atribuído à perda do sentido metafórico no momento da tradução, ou ainda, à variação lexical que pode ocorrer ao tentar se traduzir uma metáfora, fazendo com que a lexia verdade não ocorra na versão me português desta metáfora. Destacamos, aqui, a segunda ocorrência encontrada em língua inglesa, uma vez que, ao darmos mais atenção a ela, pode-se dizer que some deeper truth pode ser tanto classificado como um local profundo, como um canyon, ou uma caverna ou gruta, quanto como pode-se dizer que se refere a um recipiente bastante profundo. Optamos por classificála como um lugar, haja vista que a primeira imagem que evocamos ao analisá-la foi, de fato, um local, conforme mencionado anteriormente.

Já, o quadro 2, apresenta a metáfora conceptual $A$ verdade é um sentimento, conforme podemos observar a seguir.

Metáfora Conceptual: A verdade é um sentimento Corpus Inglês As much as the truth might be a relief, it's also Corpus Português the toughest thing he'll ever have to face.

Quadro 2: Metáfora conceptual a verdade é um sentimento

As ocorrências apresentadas neste quadro deixam clara a presença da metáfora conceptual a verdade é um sentimento, em ambos os corpora de estudo, haja vista que são exemplos correspondentes, e que, de fato, a verdade é tida como um sentimento, o alívio (relief).

Por sua vez, o quadro 3 nos mostra a metáfora conceptual de AVerdade é algo que precisa ser conhecido/revelado. Observe:

\begin{tabular}{|l|l|}
\hline \multicolumn{2}{|c|}{$\begin{array}{c}\text { Metáfora Conceptual: A verdade é algo que precisa ser } \\
\text { conhecido/revelado }\end{array}$} \\
\hline Corpus Inglês & Corpus Português \\
\hline $\begin{array}{l}\text { I may be angry, but I need to } \\
\text { know the truth. }\end{array}$ & Preciso saber a verdade. \\
\hline $\begin{array}{l}\text { And the absolute truth lies } \\
\text { the better part of decorum. }\end{array}$ & $\begin{array}{l}\text { Em algum lugar entre } \\
\text { uma blusa dos Marlins e a } \\
\text { verdade absoluta, existe } \\
\text { um pouco de decoro. }\end{array}$ \\
\hline $\begin{array}{l}\text { Or the truth that will change } \\
\text { your life. }\end{array}$ & $\begin{array}{l}\text { Ou a verdade que vai } \\
\text { mudar sua vida. }\end{array}$ \\
\hline And learn the hard truth. & $\begin{array}{l}\text { Aprender a dura verdade. } \\
\text { And the truth is revealed to } \\
\text { all. }\end{array}$ \\
$\begin{array}{l}\text { Quando as máscaras } \\
\text { finalmente saem e a } \\
\text { verdade é revelada a } \\
\text { todos. }\end{array}$ \\
\hline
\end{tabular}

Quadro 3: Metáfora conceptual a verdade é algo que precisa ser conhecido/revelado

As ocorrências encontradas em nosso corpus de estudo em português permitem-nos perceber a noção de verdade como algo que precisa ser conhecido, revelado. No corpus de estudo em inglês, a ocorrência que mais salta aos olhos é a última (And the truth is revealed to all). Esta ocorrência diz que a verdade é revelada a todos. Ora, entendemos, assim, que a verdade passou a ser de conhecimento de todos, e por isso, julgamos que esta ocorrência deva ser classificada junto às demais, tendo como referência a metáfora conceptual mencionada.

Contudo, pode-se perceber que o segundo exemplo apresentado em nosso quadro (And the absolute truth lies the better part of decorum) não trata de frases correspondentes. Ressaltamos que elas foram apresentadas desta forma, por tratarem da verdade absoluta, sendo esta correspondente e presente em ambos os exemplos, embora apareça em contextos diferentes. Cabe dizer, ainda, que estes exemplos foram agrupados, junto aos demais, sob esta metáfora conceptual, pois entendemos que a verdade absoluta remete à ideia de um conhecimento absoluto, ou seja, algo que precisa ser totalmente conhecido, revelado a todos. 
No quadro 4, apresentamos as ocorrências encontradas que tem como referência a metáfora conceptual $A$ verdade é como uma entidade/ser.

Metáfora Conceptual: A verdade como entidade/ser Corpus Inglês Corpus Português

They say the truth will set

Dizem que a verdade you free. liberta.

Because the truth hasn't

helped anybody.

Pois a verdade não ajudou a ninguém.

I had to protect you from the truth.

I'm facing the truth.

They are left to wonder if they can handle the truth.

Another way the truth comes out When you don't even mean it to...

When the mask finally comes off and the truth is revealed to all.

But be careful, since the truth can be eye-opening. Only because you couldn't deal with the truth.

But the worst thing the truth can do is when you finally tell it, it doesn't set you free, but locks you away forever.

\begin{tabular}{|l|l|} 
& sempre. \\
\hline $\begin{array}{l}\text { Guess it's the truth that's } \\
\text { getting massaged. }\end{array}$ & - \\
\hline $\begin{array}{l}\text { Or the truth you prayed } \\
\text { would never see. }\end{array}$ & - \\
\hline $\begin{array}{l}\text { And tell Serena the ugly } \\
\text { truth. }\end{array}$ & - \\
\hline- & $\begin{array}{l}\text { Mas é a verdade } \\
\text { mascarada. }\end{array}$ \\
\hline- & A verdade sempre volta. \\
\hline
\end{tabular}

Quadro 4: Metáfora conceptual a verdade como entidade/ser

Segundo mostram os exemplos deste quadro, é possível perceber, com certa clareza em na maioria das ocorrências, as características tipicamente humanas ou de entidades, como a verdade como alguém que usa máscara (Mas é a verdade mascarada), ou algo ao qual se reza (Or the truth you prayed would never see), que são atribuídas à verdade. Além disso, notamos que essa metáfora ocorre com mais frequência no corpus de estudo em inglês.
Por último, apresentamos o quadro 5, que traz as ocorrências relacionadas à metáfora conceptual $A$ verdade é um objeto.

Metáfora Conceptual: A verdade é um objeto Corpus Inglês It's not my mom's fault that the truth came out.

He's going to find out the truth.

Help Louis see the truth about Blair.

Chuck tried to cover up the truth about my mother.

A half-truth is a whole lie.

But the kind of truth I'm most

thankful for the one you never see coming hat falls right into your lap.

Looks like the price of truth.

Something tells me the truth

is just out of focus.

Most times, when people

don't offer the truth, it's

because they're afraid of what someone might think.

I like to see the truth.

Whether the truth's in a diary

or the daily news...

Chuck-He's just like his

father. He lied to me. He lied

to you, and... He tried to

cover up the truth about my mother.

Ok like cold, hard cash an get you the cold, hard truth. Look, we can keep blaming each other for what happened that night, or we can admit a harder truth... it was no one's fault.

Do you ever consider you don't know the entire truth?

Wake up, Upper East Siders, it's time to awake from our slumber and learn the hard truth...

Yeah, but the truth has

shades of gray, right?

When the truth fails you.

But some truth comes at a

price.

Chuck's searching for the

truth about his real father.

The only way to get the truth is to find him.

A verdade já vazou.

Quadro 5: Metáfora conceptual a verdade é um

objeto bem no seu colo.
Corpus Português

Não é culpa da minha mãe que a verdade veio à tona.

Ele vai descobrir a verdade.

Ajude Louis a ver a verdade.

Chuck tentou esconder a verdade sobre minha mãe. Uma meia verdade é uma mentira inteira.

Mas o tipo de verdade que eu mais agradeço, é aquela que você não percebe, que cai

Parece o preço da verdade.

Algo me diz que a verdade está fora do foco.

Na maioria das vezes que a pessoa não oferece a verdade, é porque ela tem medo que do que alguém pode pensar. Eu gosto de ver a verdade.

A verdade pode estar num diário

Chuck é como o próprio pai.

Ele mentiu para mim, mentiu para você, e... Ele tentou encobrir a verdade.

Dinheiro frio e duro para te mostrar a verdade fria e dura. Olha, podemos continuar nos culpando pelo que aconteceu aquela noite, ou podemos admitir a verdade...

Quando me julgou, considerou que não sabe toda a verdade? Levantem, Upper East Siders, hora de acordar da soneca e aprender a dura verdade. 
Os exemplos apresentados acima permitem que se perceba a presença da metáfora conceptual ressaltada aqui (a verdade é um objeto), haja vista que é possível ver a relação da verdade com os objetos concretos, dos quais algumas características são atribuídas à verdade, como algo que vem à tona, como em It's not my mom's fault that the truth came out/Não é culpa da minha mãe que a verdade veio à tona; ou algo que está em foco ou não, como em Something tells me the truth is just out of focus/Algo me diz que a verdade está fora do foco.

Passamos agora, à análise dos dados obtidos por meio da investigação das palavras coração e heart.

\subsection{Heart/Coração}

O procedimento de busca e análise das ocorrências das lexias verdade e truth foi o mesmo utilizado para as lexias coração e heart que ora apresentamos. Com estas, no entanto, obtivemos um total de 148 ocorrências para a lexia heart, das quais 53 apresentaram a presença de algum traço metafórico no corpus em inglês. Já, no corpus em português, obtivemos 89 ocorrências da lexia de busca coração, sendo que destas, 44 apresentaram a presença de algum traço metafórico.

Notamos, no entanto, que a diferença no número total de ocorrências nos dois corpora de estudo é menor do que a diferença apresentada entre os dois corpora de estudo para as palavras verdade e truth (977 ocorrências em português e 262 ocorrências em inglês), conforme dito anteriormente. Acreditamos que isto se deve ao fato de coração e heart apresentarem correspondência de uso maior em ambos os idiomas que compõem nossos corpora de estudo.

Assim, conseguimos identificar em nossos corpora de estudo a presença de sete metáforas conceptuais entre as ocorrências que contam com algum traço metafórico. O quadro a seguir mostra as ocorrências classificadas como pertencentes à metáfora conceptual $O$ coração é um lugar.

\begin{tabular}{|c|c|}
\hline \multicolumn{2}{|c|}{ Metáfora Conceptual: O coração é um lugar } \\
\hline Corpus Inglês & Corpus Português \\
\hline $\begin{array}{l}\text { There's a clear winner in the } \\
\text { war for your heart. }\end{array}$ & $\begin{array}{l}\text { Um claro vencedor na } \\
\text { guerra para o seu coração. }\end{array}$ \\
\hline $\begin{array}{l}\text { I won't, as long as I keep my } \\
\text { heart locked away and our } \\
\text { interactions off the street. }\end{array}$ & $\begin{array}{l}\text { É só manter meu coração } \\
\text { trancado. }\end{array}$ \\
\hline $\begin{array}{l}\text { I'm closing my heart to you } \\
\text { forever. }\end{array}$ & $\begin{array}{l}\text { Fecharei meu coração para } \\
\text { você para sempre. }\end{array}$ \\
\hline $\begin{array}{l}\text { Because when you open } \\
\text { your heart. }\end{array}$ & $\begin{array}{l}\text { Porque quando abrimos } \\
\text { nosso coração. }\end{array}$ \\
\hline I still hold him in my heart. & $\begin{array}{l}\text { Eu ainda o tenho no } \\
\text { coração. }\end{array}$ \\
\hline $\begin{array}{l}\text { Chuck opened his heart to } \\
\text { you, and now his future lies } \\
\text { in your hands... }\end{array}$ & $\begin{array}{l}\text { Chuck abriu o coração para } \\
\text { você. }\end{array}$ \\
\hline $\begin{array}{l}\text { Maybe she is, maybe she } \\
\text { isn't. Why the sudden change } \\
\text { of heart? }\end{array}$ & $\begin{array}{l}\text { Talvez sim, talvez não. Por } \\
\text { que a mudança repentina } \\
\text { de coração? }\end{array}$ \\
\hline You are still in her heart. & $\begin{array}{l}\text { Você ainda está no } \\
\text { coração dela. }\end{array}$ \\
\hline $\begin{array}{l}\text { You'd think she'd be a pro by } \\
\text { now, but I don't know. Her } \\
\text { heart doesn't really seem in } \\
\text { it. }\end{array}$ & $\begin{array}{l}\text { O coração dela não parece } \\
\text { estar nisso. }\end{array}$ \\
\hline $\begin{array}{l}\text { She tells all about who's } \\
\text { really in her heart. }\end{array}$ & \\
\hline $\begin{array}{l}\text { Now, that she revealed } \\
\text { what's in her heart. }\end{array}$ & \\
\hline $\begin{array}{l}\text { We just answered who is in } \\
\text { Blair's heart. }\end{array}$ & \\
\hline $\begin{array}{l}\text { Just let me earn back a place } \\
\text { in your heart. }\end{array}$ & \\
\hline $\begin{array}{l}\text { Thank you both from the } \\
\text { bottom of my heart. }\end{array}$ & \\
\hline $\begin{array}{l}\text { Tell your prince where your } \\
\text { heart truly lies. }\end{array}$ & \\
\hline $\begin{array}{l}\text { He hasn't had a change of } \\
\text { heart. }\end{array}$ & \\
\hline $\begin{array}{l}\text { I find it in my heart to forgive } \\
\text { you for kissing another. }\end{array}$ & \\
\hline $\begin{array}{l}\text { It's an open heart That's } \\
\text { vulnerable to the deepest } \\
\text { wound. }\end{array}$ & \\
\hline- & $\begin{array}{l}\text { A chave da minha suíte, do } \\
\text { coração do Nate e da sua } \\
\text { felicidade. }\end{array}$ \\
\hline
\end{tabular}

Quadro 6: Metáfora conceptual o coração é um lugar

Conforme podemos perceber, ao coração são atribuídas várias características de diferentes lugares, desde um lugar que pode ser trancado, até mesmo a um lugar em que ocorre uma guerra, ou no qual se mantém algo ou alguém. Algo que nos parece peculiar são as ocorrências, em ambos os corpora, que dizem respeito a uma mudança de coração, como se determinado coração já não fosse mais interessante, e por isso, o indivíduo muda de coração, 
como se mudasse de um lugar a outro. É evidente, também, o maior número de ocorrências dessa metáfora conceptual no corpus de estudo em inglês, fato que pode ser explicado pelo maior número de ocorrências resultantes para a palavra de busca heart e, também, pelo fato de algumas ocorrências apresentadas em língua inglesa se referirem ao mesmo uso desta metáfora, como é o caso de She tells all about who's really in her heart; e Now, that she revealed what's in her heart, que fazem referência ao coração como um lugar no qual se mantém algo ou alguém.

O quadro a seguir nos mostra a metáfora conceptual $O$ coração é um prêmio, e sua ocorrência.

Metáfora Conceptual: O coração é um prêmio

Corpus Inglês $\quad$ Corpus Português

Because that's how you win -

a guy's heart.

Quadro 7: Metáfora conceptual o coração é um prêmio.

Esta metáfora conceptual apresenta apenas uma ocorrência no corpus de estudo em inglês. No entanto, esta única ocorrência deixa evidente a caracterização de heart como um prêmio, como aquilo que se recebe no ato da vitória.

Por sua vez, o quadro 8 evidencia as ocorrências que encontramos para a metáfora conceptual O coração é razão/sabedoria. Observe:

Metáfora Conceptual: O coração é razão/sabedoria Corpus Inglês Anne Boleyn thought only with her heart and she got her head chopped off. Corpus Português Ana Bolena só pensava com o seu coração e foi decapitada.

I knew in my heart you didn't send it.

Eu sabia no meu coração, você não tinha enviado isso.

\begin{tabular}{l|l}
\hline But I always knew in my & Mas eu sempre soube no
\end{tabular}
heart that what l'd felt for Kim-ly was true love.

I think you know it by heart. meu coração.

Te diria o final dessa história, mas acho que sabe de cor.

\section{I think in your heart you know}

that.

You know in your heart that

this is truth.

Quadro 8: Metáfora conceptual o coração é

razão/sabedoria
Com estas ocorrências, podemos perceber que ao coração são atribuídas algumas características típicas da razão, da sede do saber, e que, nestes casos, o coração deixa de ser a sede do sentimento, como é comumente considerado. É possível identificarmos características racionais atribuídas ao coração, como em Anne Boleyn thought only with her heart and she got her head chopped off/Ana Bolena só pensava com o seu coração e foi decapitada, fato que evidencia a metáfora conceptual destacada aqui.

A seguir, apresentamos as ocorrências nas quais evidenciamos a metáfora conceptual $O$ coração é uma entidade/ser.

\begin{tabular}{|c|c|}
\hline \multicolumn{2}{|c|}{$\begin{array}{c}\text { Metáfora Conceptual: O coração como } \\
\text { entidade/ser }\end{array}$} \\
\hline Corpus Inglês & Corpus Português \\
\hline $\begin{array}{l}\text { I can literally feel my heart } \\
\text { thump when I see him. }\end{array}$ & $\begin{array}{l}\text { Posso sentir literalmente } \\
\text { meu coração pulando } \\
\text { quando o vejo. }\end{array}$ \\
\hline $\begin{array}{l}\text { Underneath that smile is a } \\
\text { heart of killer. }\end{array}$ & $\begin{array}{l}\text { Por trás desse sorriso há } \\
\text { um coração assassino. }\end{array}$ \\
\hline $\begin{array}{l}\text { Absence makes the heart } \\
\text { grow fonder. }\end{array}$ & $\begin{array}{l}\text { Ausência faz o coração } \\
\text { crescer amoroso. }\end{array}$ \\
\hline $\begin{array}{l}\text { We have to help her hear } \\
\text { her heart. }\end{array}$ & $\begin{array}{l}\text { Precisamos ajudá-la a } \\
\text { ouvir seu coração. }\end{array}$ \\
\hline $\begin{array}{l}\text { If you go back with_an } \\
\text { uncertain heart. }\end{array}$ & $\begin{array}{l}\text { Se voltar com um coração } \\
\text { indeciso. }\end{array}$ \\
\hline $\begin{array}{l}\text { She has great heart, style, } \\
\text { and grace... Even when she } \\
\text { get mad. }\end{array}$ & $\begin{array}{l}\text { Ela tem um bom coração, } \\
\text { estilo, graça. }\end{array}$ \\
\hline $\begin{array}{l}\text { It is often our heart that gets } \\
\text { the biggest workout. }\end{array}$ & $\begin{array}{l}\text { Frequentemente é o } \\
\text { coração que tem o maior } \\
\text { trabalho. }\end{array}$ \\
\hline $\begin{array}{l}\text { I'll manage matters of my } \\
\text { heart. }\end{array}$ & $\begin{array}{l}\text { Eu lidarei com os } \\
\text { problemas do coração. }\end{array}$ \\
\hline $\begin{array}{l}\text { How about your spare me } \\
\text { the heartache and yourself } \\
\text { the humiliation and give up } \\
\text { on this failed experiment in } \\
\text { rebellion? }\end{array}$ & $\begin{array}{l}\text { Que tal me poupar à dor } \\
\text { no coração e a si mesmo a } \\
\text { humilhação e desistir desta } \\
\text { experiência fracassada de } \\
\text { rebelião? }\end{array}$ \\
\hline $\begin{array}{l}\text { And out of the goodness of } \\
\text { your heart. }\end{array}$ & $\begin{array}{l}\text { E pelo bem no seu } \\
\text { coração, você veio para o } \\
\text { resgate. }\end{array}$ \\
\hline $\begin{array}{l}\text { My daughter has a good } \\
\text { heart. }\end{array}$ & $\begin{array}{l}\text { Minha filha tem um bom } \\
\text { coração. }\end{array}$ \\
\hline It may hurt my heart. & - \\
\hline $\begin{array}{l}\text { Serena's needs to keep an } \\
\text { eye on her heart. }\end{array}$ & - \\
\hline
\end{tabular}

Quadro 9: Metáfora conceptual o coração é uma entidade/ser.

Aqui, assim como ocorre com a metáfora conceptual de que a verdade é uma/um entidade/ser, 
são atribuídas características humanas, ou de entidades, ao coração, e este passa a ser alguém que precisa ser ouvido, como em We have to help her hear her heart/ Precisamos ajudá-la a ouvir seu coração; ou que, até mesmo, é assassino, como em Underneath that smile is a heart of killer/Por trás desse sorriso há um coração assassino. Também se pode perceber que há mais ocorrências desta metáfora conceptual em nosso corpus em inglês do que em nosso corpus em português, podendo essa diferença ser resultado da perca do sentido metafórico ao se fazer a tradução para o português e/ou à utilização de escolhas lexicais diversas de coração, o que manteria o sentido metafórico, mas ocasionaria uma metáfora que não abrangesse a lexia coração.

A seguir, apresentamos a metáfora conceptual O coração é um objeto, e as ocorrências encontradas em nossos corpora de estudo.

\begin{tabular}{|c|c|}
\hline \multicolumn{2}{|c|}{ Metáfora Conceptual: O coração é um objeto } \\
\hline Corpus Inglês & Corpus Português \\
\hline $\begin{array}{l}\text { My heart was always in } \\
\text { the same place. }\end{array}$ & $\begin{array}{l}\text { Meu coração estava } \\
\text { sempre no mesmo lugar. }\end{array}$ \\
\hline $\begin{array}{l}\text { And you have a big } \\
\text { heart, just like your } \\
\text { father. }\end{array}$ & $\begin{array}{l}\text { Você tem um coração } \\
\text { grande igual ao seu pai. }\end{array}$ \\
\hline $\begin{array}{l}\text { You're giving your heart } \\
\text { to a money grubbing } \\
\text { harlot. }\end{array}$ & $\begin{array}{l}\text { Está dando seu coração } \\
\text { a uma prostituta } \\
\text { interesseira. }\end{array}$ \\
\hline $\begin{array}{l}\text { Maybe you should guard } \\
\text { your heart. }\end{array}$ & $\begin{array}{l}\text { Talvez devesse guardar } \\
\text { o coração. }\end{array}$ \\
\hline $\begin{array}{l}\text { A dozen roses in one } \\
\text { hand, his heart in the } \\
\text { other. }\end{array}$ & $\begin{array}{l}\text { Uma dúzia de rosas em } \\
\text { uma mão, seu coração } \\
\text { na outra. }\end{array}$ \\
\hline $\begin{array}{l}\text { My heart belongs to } \\
\text { Asher. }\end{array}$ & $\begin{array}{l}\text { É só que meu coração } \\
\text { pertence ao Asher. }\end{array}$ \\
\hline $\begin{array}{l}\text { And while it warms my } \\
\text { heart hearing that, I'm } \\
\text { late. }\end{array}$ & $\begin{array}{l}\text { E por mais que isso } \\
\text { aqueça meu coração, } \\
\text { estou atrasada. }\end{array}$ \\
\hline $\begin{array}{l}\text { Nate Archibald suffering } \\
\text { from a broken heart. }\end{array}$ & $\begin{array}{l}\text { Nate Archibald sofrendo } \\
\text { de coração partido. }\end{array}$ \\
\hline $\begin{array}{l}\text { They say it's a broken } \\
\text { heart, but... I hurt in my } \\
\text { whole body. }\end{array}$ & $\begin{array}{l}\text { Dizem que é um coração } \\
\text { partido, mas... Meu corpo } \\
\text { inteiro dói. }\end{array}$ \\
\hline $\begin{array}{l}\text { I'm not heartbroken. I'm } \\
\text { humiliated. }\end{array}$ & $\begin{array}{l}\text { Eu não estou com o } \\
\text { coração partido. Estou } \\
\text { humilhada. }\end{array}$ \\
\hline $\begin{array}{l}\text { It's a really weird, } \\
\text { embarrassing for a } \\
\text { college guy to be } \\
\text { admitting, but I... Losing } \\
\text { Milo broke my heart. }\end{array}$ & $\begin{array}{l}\text { É muito estranho e } \\
\text { vergonhoso para um } \\
\text { universitário admitir, mas } \\
\text { perder Milo me partiu o } \\
\text { coração. }\end{array}$ \\
\hline $\begin{array}{l}\text { No one wants a soft- } \\
\text { hearted has-been who's } \\
\text { worried about dating }\end{array}$ & $\begin{array}{l}\text { Ninguém quer um } \\
\text { coração mole que está } \\
\text { preocupado em namorar }\end{array}$ \\
\hline
\end{tabular}

\begin{tabular}{|l|l|}
\hline Blair Waldorf. & Blair Waldorf. \\
\hline $\begin{array}{l}\text { We will show the world } \\
\text { where her true heart lies. }\end{array}$ & - \\
\hline $\begin{array}{l}\text { Chuck's given his heart } \\
\text { away }\end{array}$ & - \\
\hline
\end{tabular}

Quadro 10: Metáfora conceptual $O$ coração é um objeto.

Esta metáfora conceptual também se mostrou bastante utilizada em ambos os corpora de estudo, apresentando o mesmo número de ocorrências em ambos. Ressaltamos, contudo, que as características de objetos atribuídas a coração e heart são as mais variadas, e que isso se deve ao fato de tomarmos como base os mais diferentes objetos para serem comparados ao coração, desde algo que se possa segurar em uma das mãos, como em $A$ dozen roses in one hand, his heart in the other/Uma dúzia de rosas em uma mão, seu coração na outra; até mesmo a algo que é quebrado, partido, como em They say it's a broken heart, but...I hurt in my whole body/Dizem que é um coração partido, mas... Meu corpo inteiro dói.

No que diz respeito à metáfora conceptual $O$ coração é um recipiente, apresentamos o quadro a seguir:

\begin{tabular}{|l|l|}
\hline \multicolumn{2}{|c|}{ Metáfora Conceptual: O coração é um recipiente } \\
\hline Corpus Inglês & Corpus Português \\
\hline I have peace in my heart. & $\begin{array}{l}\text { Fico com a paz no } \\
\text { coração. }\end{array}$ \\
\hline $\begin{array}{l}\text { I can't tell you how my } \\
\text { heart filled with joy. }\end{array}$ & $\begin{array}{l}\text { Mal consigo expressar } \\
\text { como meu coração } \\
\text { encheu-se de alegria. }\end{array}$ \\
\hline $\begin{array}{l}\text { I have so much love in my } \\
\text { heart for that girl. }\end{array}$ & $\begin{array}{l}\text { Tenho muito amor em meu } \\
\text { coração por essa garota. }\end{array}$ \\
\hline $\begin{array}{l}\text { The vengeance of hell boils } \\
\text { in my heart. }\end{array}$ & $\begin{array}{l}\text { A vingança do inferno } \\
\text { ferve no meu coração. }\end{array}$ \\
\hline $\begin{array}{l}\text { And out of the goodness of } \\
\text { your heart, you came to his } \\
\text { rescue. }\end{array}$ & $\begin{array}{l}\text { E pelo bem no seu } \\
\text { coração, você veio para o } \\
\text { resgate. }\end{array}$ \\
\hline
\end{tabular}

Quadro 11: Metáfora conceptual O coração é um recipiente.

Aqui, percebemos que o coração é visto como um recipiente que serve para conter algo, como um sentimento, por exemplo, ou como um recipiente no qual algo é metabolizado, como a ocorrência na qual a vingança ferve no coração. Embora tenhamos encontrado poucas ocorrências desta metáfora em nossos corpora de estudo, está se mostra uma metáfora comum a ambos os idiomas estudados. 
Por último, apresentamos a metáfora conceptual O coração como bússola/guia.

Metáfora Conceptual: O coração como bússola/guia Corpus Inglês She follows her heart and chose Louis. And then follow your heart to the perfect guy. I followed my heart because I love you. Corpus Português Ela seguiu seu coração, e escolheu Louis.

E siga seu coração até o cara perfeito.

Segui meu coração porque
eu amo você.

Quadro12: Metáfora conceptual o coração como bússola/guia.

Embora uma bússola possa ser caracterizada como um objeto, e um guia possa ser caracterizado como um ser ou entidade, julgamos relevante a classificação destas ocorrências dentro desta metáfora conceptual pois, tanto a bússola , como o guia, apresentam características próprias: ambos indicam a direção a ser tomada, a ser seguida, seja esta direção um caminho físico, ou uma escolha. Da mesma forma, é ao coração que cabe indicar o caminho a ser seguido nas ocorrências levantadas.

\section{Considerações finais}

Constatamos, em nossa análise, que, apesar de investigarmos dois idiomas diferentes, e estes apresentarem diferentes manifestações linguísticas, é possível afirmar que as metáforas conceptuais evidenciadas aqui ocorrem em ambos os idiomas. Além disso, as metáforas conceptuais encontradas em nosso corpus e apresentadas aqui são metáforas ontológicas, ou seja, metáforas que surgem a partir das experiências que envolvem as relações do ser humano com objetos, substâncias e entidades, de acordo com a classificação dada por Lakof e Johnson ([1980] 2003).

Embora Pérez (2009) tenha empreendido seu estudo em dados levantados em tesauros e dicionários, tomando por base afirmação de Deignan (1999), ao defender que "a investigação de um campo semântico particular pode tornar-se mais sistemática por meio do uso de um tesauros abrangente" 14 (DEIGNAN, 1999, p. 197 apud PÉREZ, 2009, p. 161), ressaltamos que, ao usar nosso corpus composto pelas legendas do seriado norte-americano Gossip Girl, conseguimos, assim como Pérez, buscar e encontrar as metáforas conceptuais de heart e truth e verdade e coração, além de ter sido possível verificar a ocorrência destas metáforas em um léxico fraseológico que perpassa a linguagem utilizada por adolescentes e jovens, público-alvo do seriado escolhido para compor nosso corpus.

Por fim, esperamos ter conseguido demonstrar a presença de metáforas conceptuais ontológicas no léxico fraseológico a partir das lexias heart/truth e verdade/coração, evidenciando a presença e importância da metáfora para a Fraseologia.

\section{Referências}

BARBOSA, T. M. Estudo contrastivo das emoções em expressões idiomáticas corporais do italiano e do português brasileiro: uma vertente cognitivista. Dissertação (Mestrado em Estudos Linguísticos) IBILCE/UNESP, São José do Rio Preto, 2014.

CORPAS PASTOR, G. Manual de fraseologia española. Madrid:Gredos, 1996.

GOSSIP GIRL. Disponível em: http://www.tvsubtitles.net. Acesso em: 01 jul. 2014.

IÑESTA MENA, E. V.; PAMIES BERTRÁN, A. Fraseología y metáfora: aspectos tipológicos y cognitivos. Granada Lingvistica, 2002.

LAKOFF, G.; JOHNSON, M. Metaphors we live by. University of Chicago Press, [1980] 2003.

PÉREZ, R. G. Estudio cognitivo-contrastivo de las metáforas del corazón en inglés y alemán. BabelAfial, 18, 2009.

TOGNINI-BONELLI, E. Corpus Linguistics at work. John Benjamins Publishing, 2001.

TRISTÁ, A. M. Fraseología y contexto. La Habana: Editorial de Ciencias Sociales, 1988.

ZULUAGA, A. Introducción al estudio de las expresiones fijas. Frankfurt: Peter. Lang, 1980.

14 "(...) the investigation of a particular semantic field can be made more systematic with the use of a comprehensive thesaurus." 


\section{COMO CITAR ESSE ARTIGO}

SABINO, Marilei Amadeu; ORENHA-OTTAIANO, Adriane; CALDAS, Ariane Donizete Delgado Ribeiro. As metáforas em Verdade e Coração: estudo contrastivo do léxico fraseológico a partir de um corpus paralelo. Signo, Santa Cruz do Sul, v. 44, n. 79, p. 143-153, jan. 2019. ISSN 1982-2014. Disponível em: <https://online.unisc.br/seer/index.php/signo/article/view/12631>. Acesso em: doi: https://doi.org/10.17058/signo.v44i79.12631. 